\section{Thank you from the guest editors on behalf of the African Journal of Health Professions Education}

\section{The AJHPE reviewers}

AJHPE called for manuscripts focused on nursing and midwifery education in Africa aligned with the 'Year of the Nurse and Midwife', as declared by the World Health Organization. More than 30 manuscripts were submitted for this special focus issue by authors from all over the continent.

On behalf of $A J H P E$, we would like to express our appreciation towards the following peer reviewers who put in hours of work, especially during this difficult time, painstakingly evaluating the quality and importance of the submitted manuscripts, providing important insights to authors and influencing editors' decisions. These peer reviewers influence the knowledge economy in nursing and midwifery education and their role has been pivotal for this special focus issue. We sincerely appreciate all your efforts and your readiness to serve in this role - thank you.

Mrs Annatjie Peters, Foundation for Professional Development, South Africa Dr Elize Venter, Foundation for Professional Development, South Africa Dr Mike Kagawa, Makerere University, Uganda

Ms Ansie Benjamin, National Health Training Centre, Namibia Dr Takaedza Munangatire, University of Namibia, Namibia Prof. Siedine Coetzee-Knoblauch, North-West University, South Africa Prof. Welma Lubbe, North-West University, South Africa Dr Tinda Rabie, North-West University, South Africa Prof. Gerda Reitsma, North-West University, South Africa Mr Francois Watson, North-West University, South Africa Ms Lianne Keiller, Stellenbosch University, South Africa Dr Sindi Mtembu, KwaZulu-Natal Nursing College, South Africa Prof. Ntombifikile Mtshali, University of KwaZulu-Natal, South Africa Dr Chivaugn Gordon, University of Cape Town, South Africa Ms Tania Buys, University of Pretoria, South Africa
Dr Werner Cordier, University of Pretoria, South Africa Prof. Rhena Delport, University of Pretoria, South Africa Mrs Corne Nel, University of Pretoria, South Africa Prof. Corne Postma, University of Pretoria, South Africa Dr Rivak Punchoo, University of Pretoria, South Africa Ms Melitah Rasweswe, University of Pretoria, South Africa Dr Astrid Turner, University of Pretoria, South Africa Prof. Neltjie van Wyk, University of Pretoria, South Africa Dr Liz Wolvaardt, University of Pretoria, South Africa Dr Johan Bezuidenhout, University of the Free State, South Africa Prof. Yvonne Botma, University of the Free State, South Africa Dr Lizemari Hugo-van Dyk, University of the Free State, South Africa Dr Champion N Nyoni, University of the Free State, South Africa Prof. Hester Julie, University of the Western Cape, South Africa Prof. Pat Mayers, University of the Western Cape, South Africa Prof. Margaret Williams, University of the Western Cape, South Africa Ms Abigail Dreyer, University of the Witwatersrand, South Africa Dr Hilary Thurling, University of the Witwatersrand, South Africa Dr Zodwa Linda, University of Zululand, South Africa Dr Doreen Mukona, University of Zimbabwe, Zimbabwe

\section{Champion N Nyoni}

Guest editor, School of Nursing, Faculty of Health Sciences, University of the Free State, Bloemfontein, South Africa

nyonic@ufs.ac.za

\section{Liz Wolvaardt}

Guest editor, School of Health Systems and Public Health, Faculty of Health Sciences, University of Pretoria, South Africa

liz.wolvaardt@up.ac.za

Afr J Health Professions Educ 2020;12(3):93. https://doi.org/10.7196/AJHPE.2020.v12i3.1443 